\title{
Fake news - a manufactured deception, distortion and disinformation is the new challenge to digital literacy \\ Dr Neha Pandey ${ }^{1}$
}

ABSTRACT

In an era of information age, the defining variable of the age i.e. information is facing a tsunami in the form of fake news. Tsunami because it came all of a sudden, created havoc and is gargantuan in proportion.

Facts have become a misnomer and reality an imagination. Confusion and chaos are the hurdle blocks for the one who wants to navigate through the digital landscape. The line between facts and fictions had been trounced. What is all the more alarming is that the fake-news tsunami is not a natural incidence but a whole business which blooms and grows on fabricated content and has become the new currency of globalized digitalization. Study on the spread of fake information, through social media and online networks, has become a significant object of scholarly research. Estimates suggest some fake news sites receive $50 \%-80 \%$ of their traffic via Facebook alone.

This paper is a sincere attempt to map fake news into digital landscape by analysing its entry, varieties and survival. It also explores the various possibilities of duping users through a combination of intention and software algorithms. In the end, the researcher analyses how digital literacy and willingness on part of users can prove as a remedy in combating the fake news virus. If anything good has come from the recent furore over fake news and its menace, it is that fake news has highlighted the importance of making sure that the information one consumes and, especially, the information one shares is credible. It is like anti-virus potion which is created automatically. Or in simpler terms, it is like cultivating the habit to consume healthy, hygienic and balanced diet and toning the cognitive immune system.

Keywords: Fake news, digital literacy, post-truth, Facebook, US elections, artificial intelligence.

Fake news - a manufactured deception, distortion and disinformation is the new challenge to digital literacy

In an era of information age, the defining variable of the age i.e. information is facing a tsunami in the form of fake news. Tsunami because it came all of a sudden, created havoc and is gargantuan in proportion.

Facts have become a misnomer and reality an imagination. Confusion and chaos are the hurdle blocks for the one who wants to navigate through the digital landscape. The line between facts and fictions had been trounced. What is all the more alarming is that the fake-news tsunami is not a natural incidence but a whole business which blooms and grows on fabricated content and has become the new currency of globalized digitalization.

We read without understanding and believe without introspecting. The creative spirit of human cognition is drugged and slowly bruising the most important function of the attribute which makes us human, a thinking being.

Fake news has found its powerful and protective abode in Facebook, Twitter and WhatsApp which

1 Assistant Professor, Department of Journalism and Mass Communication, Banaras Hindu University, Varanasi -221005 have become comfy avenues for politicians to spread misinformation, rumour, falsehood and lies.

\section{Research Support}

Study on the spread of fake information, through social media and online networks, has become a significant object of scholarly research. Scholars have theorized that fake news can exercise a significant degree of influence on political campaigns and discussions. Although extensive research exists on political misinformation, there is some contest about the extent to which fake news influences public opinion, including social media "echo chambers" and "filter bubbles". (Roozenbeek, Linden, 2018)

This provides scope for further research on the intent and content of fake news and establishing relations between them. At present, deliberate and verifiably false and misleading articles have contributed to an increasingly uncertain digital climate.

The barriers to entry for producing such content have dropped precipitously due to the ascend of the interne users, given how easy it is to set up a website or social media page and monetize it through advertising. This has led to the proliferation of fake news among news media outlets in general. 
There is also an increased reliance of individuals on social media as a platform to access the news. This has been confirmed in a study by the Pew Research Centre which reported that $62 \%$ of US adults now cite social media sites as one of their news sources'.(Shearer, Gottfried, 2017)

Competitive Damage: This development has caused traditional media outlets to embrace stories that are trending on social media, without essentially having a clearly defined policy for verifying the content before it is broadcasted. This has resulted in an uptick in newsreaders' exposure to fake news. At the same time, it has also put a question mark on the reliance level of these traditional media among users.

\section{Facebook Links}

There is no denying the fact that fake news stories can be, and for a long time have been, transmitted through conventional media outlets, such as print and radio broadcasting, social media is facilitating their dissemination and profitability like never before. Estimates suggest some fake news sites receive $50 \%-80 \%$ of their traffic via Facebook alone. (Vezér, 2017)

\section{Advertisement Traffic}

Engagement has become a bigger player than factual information. The motivations for publishing fake news range from systematically misinforming for political or other reasons to generating advertising revenues. Indeed, as social media users engage with fake news stories, fake news publishers collect revenues from advertisers who pay fees in proportion to website traffic. Social media networks are fertile grounds for fake news because their revenue models reward content engagement rather than content quality. (Hubbard, 2017)

\section{Fake news and chaos}

Fake news creates confusion, which can have pernicious effects. The notorious "pizzagate" fake news story, which led a would-bevigilante to bring a gun into a Washington, DC pizza restaurant and open fire, is only one example of the danger fake news can pose to the public. (Fisher, Cox, Hermann, 2016)

According to survey data from the Pew Research Center, nearly two-thirds of Americans say that fake news has caused them a great deal of confusion, and just under one-quarter have shared a made-up news story. ( Mitchell, Barthel, Holcomb, 2016)

Fake news may also have deleterious political consequences, as fabricated stories can be designed with the intent to influence elections and undermine democratic processes. (Timberg, 2016). Concerned with such grave issues, governments need to gear up to prevent fake news from distorting their political, social and cultural landscapes.

\section{Historical milieu}

The concept of 'fake' news stories is nothing new and has been around for centuries in the form of propaganda, yellow journalism, conspiracy theories, or hoaxes; thus spreading disinformation.

Just one week after the 2016 presidential election, when tens of millions of Hillary supporters were still in absolute shock that Donald Trump actually beat her - and while many Trump supporters were in a similar state of surprise- the term "fake news" became the talk of the town and quickly turned into one of the most loaded and controversial labels in America. It was an issue that got more polarizing, complex, deeper and darker.

The most interesting observation of the times was that it was not the ordinary right-wing news sites highlighting the reasons why Hillary was wrong for the job, or documenting her history of corruption and scandals. It was supposed "fake news" articles that were posted on little-known websites and then spread virally through Facebook by people sharing them. People must have been duped into not trusting or disliking Hillary Clinton because they read lies about her on Facebook, the favorite book of the digitalgeneration. (Dice, 2017)

\section{Alarming Bell which is still Ringing}

The Washington Post led the charge and sounded the alarm with a headline reading, "Facebook fake-news writer: 'I think Donald Trump is in the White House because of me." (Dewet, 2016) An avalanche of accusations followed, causing a moral panic in the mainstream media as they tried to warn the world about this newly discovered 'danger.' Rolling Stone magazine immediately echoed this new battle cry with the headline, "How a Fake Newsman Accidentally Helped Trump Win the White House." (Hedegaard, 2016)

A new scandal erupted claiming the Russians were behind the new fake news phenomenon as part of a plot to install Trump as their "puppet president." The Washington Post, which was dedicated to stopping Donald Trump from becoming president, came out with an article, "Russian Propaganda Effort Helped Spread 'Fake News' During Election, Experts Say," which claimed that the fake news stories about Hillary 
Clinton were part of a dis-information operation launched by the Russians in order to help Donald Trump win. (Timberg, 2016)

It has been observed and reported that the top fabricated US presidential election stories generated more engagement (i.e. shares, reactions or comments) on Facebook than did the top election stories in mainstream outlets, including the New York Times, Washington Post, Huffington Post and NBC News. It was an uncontrolled influx and an unprecedented kind of assault by imposters masquerading as reporters who are using the digital weapon of fake news to poison the media landscape with lies. (Moinuddin, Melissa, Vezér, Morrow, 2017)

\section{Forms of Fake News}

In the broadest definition, then, fake news is any information that is intentionally created under the pretense that it is credible when, in reality, it is not. Here is a brief description of different kinds of fake news as researched from different relevant literature.

Journalist Claire Wardle identifies seven types of "mis and disinformation": -1. Satire or parody 2.Misleading content 3 . Imposter content 4. Fabricated content 5.False connection 6.False context 7.Manipulated content.

Visual grammar of fake news identifies its other cousins. Mercenary fake news is created for the purpose of making money with no intent on the part of its creators to further any particular political agenda. The entire financial transaction is entirely based on the number of visitors. Although each payment is small, total payments can add up to large sums.

A recent examples point out towards this moneymaking trend. In August 2016 the Guardian reported that teenagers in the small townofVeles, Macedonia, were running over 150 websites featuring mostly pro-Donald Trump fake new articles. Rather than having any politically motivated interest in the US elections, the owners of these websites were creating fake news stories as a way to earn money. The websites featured pro-Trump articles simply because these generated more income than pro-Clinton articles.

When fake news is intentionally created to promote a specific agenda, it becomes propaganda. An entirely different genre of fake news consists of satirical stories create for purposes of humor as well as, in many cases, political or social commentary. Those who can't understand the satire, consider it true word by word.(Barclay, 2018)

\section{HOW and WHY - Decoding Fake News Process}

The Washington Post pointed out a few of the most popular (actual) fake news articles, and named the man behind them - Paul Horner, a 38-yearold Internet entrepreneur who ran CNN.com.de, CBSnews.com.co, NBC.com.co, ABCnews.com.co, and other fake news websites which were designed to look like actual news sites and used similar URLs. (Dice 2017)

Most fake news and satire websites simply want to make money from the web traffic their articles bring to the sites. The way most website advertising works is that Google Ad Sense (or other ad companies) pay them per page visit, so if the site can create sensational headlines and get lots of people to post links to their articles on Facebook it will drive a lot of traffic to their site and they get paid.

Fake content posted on any social platform has complex consequences regarding how it spreads offline and online, how the trending lists function to restrict certain stories from going viral and artificially aid others to do just the opposite, role these companies have in distributing (and suppressing) user generated content, and if information flowing through these platforms influences their audience.

\section{Mimicry tantrums and tricks}

Fake news website share traits with mimicry artists. They try to look-alike eyes-accustomed articles. Shady websites pop up which are cleverly designed to look like actual news sites or have names sounding like a newspaper from a major city. They meticulously copy the layout, look, feel, font and color of authentic news websites. Then they post fake news stories which go viral, bring traffic to their site and in the process earn some ad revenue or get some laughs from the joy of pranking people. These fake stories trick a small number of people and many users succumb to their click bait titles out of curiosity as they mimic brands (of trustworthy media outlets). The process does not end here. The same stories are then shared by these users without even blinking an eye because the power of spreading is at the click of a button or smart touch. Click is faster than blink.

The next stage is already prepared. The trending boxes through artificial algorithms would start compiling lists of the most talked about topics, giving active users an insight into what is trending and ascending the trend further. The vicious cycle of posting and reposting continues. 


\section{Other factors}

If the concept of fake news is not new, the ways to spread and manipulate it, is new. The Internet, social media and the advancing technologies have made it very easy to peddle and promote lies.

\section{Digital War}

Digital technology makes it easy to alter information-including photographs, audio recordings, and video-for the purposes of misleading the recipients of that information by morphing the content and context altogether. A number of pretty new technologies give purveyors of misinformation sophisticated tools for hauling out deceptions. Not only this, political bots produce machine-generated content, such as tweets, that may falsely appear to be and confused with human-generated content. Advanced software makes it possible to create machine-written articles that require minimal human input. As with tweets produced by political bots, these articles may falsely appear to be generated by humans. The final work is done by search engine optimization which can mislead by re-ranking search engine results to drive less credible information to the top of a results list while driving more credible information to the bottom.(Barclay, 2018)

The fact is there are huge monetary rewards to writing just the right headline to attract clicks and eyeballs. Clicks equal advertising dollars. They also attract sponsors who pay people to generate vast numbers of posts on Twitter, Facebook, and other social media. This makes it's the current lucrative business. (Bartlett, 2017)

\section{Middleman}

Overtime, this has made Facebook and Twitter a "middleman" which now stands in between people and the websites they used to visit directly by typing in the URLs. at Facebook and Twitter and see how they can, and do, manipulate and censor information for political reasons and to subtly shift the opinions of users. This manipulation offers limitless ramifications and dystopian possibilities.

If someone posts something that contains certain keywords that Facebook through its advanced software has determined they do not want to go viral for specific reason, their algorithms filter it out and prevent the post from popping up. (O'Brien, 2016)

At its onset, Facebook only showed users what their 'friends'were posting, but that changed when they added the trending module - and with this simple little box they harnessed the power to introduce their one billion users to news stories that their friends hadn't posted - stories the company feels users should know about, and overnight Facebook transformed from just a social networking site to a news company. This was the game-changing renaissance. Facebook became a powerful, modern day, digitally-smart gatekeeper that can decide which stories willgo viral, and which ones will remain virtually unknown. Twitter, also censors and promotes certain hashtags, tweets, and trending topics.

\section{Why one Shares Fake News: Online Behavior Analysis}

"Fake news" is real. It's tricky to define and identify, but it's crucial to understand its long term consequences and dangers. Imagine a world where the digital landscape is only flooded with fake content and real stories being left to drown.

Originally, "fake news" meant stories published to drive traffic to websites so the owners could make money. The information was false; the writers knew this. But the irony is that readers don't know. The term gained popularity during the 2016 U.S. presidential campaign - and is now often used to describe hyper-political sites. Fake news story, like cancer cells, proliferated so quickly that now it has emerged as a new beat in itself.

But one needs to slice and analyze that who are the partners along with their generators and software who are actively heralding this proliferation of fake content. "These stories wouldn't spread if people didn't spread them. They spread on social media, where users are "broadcasters as well as consumers of news," said Johnson. One needs to inculcate an ethical responsibility to make sure that a story is legitimate before spreading it to our peers. Digital technology, including social media, has a "click-and-leave" economy, said John Macnab. It encourages users to respond quickly to endless information, but no expert helps them determine what's trustworthy.

The term creates distrust. People hear something is "fake news" and may assume it's incorrect, even without hearing the news itself. It's part of a larger trend. Oxford Dictionaries declared "posttruth" 2016's word of the year. The adjective describes circumstances in which objective facts are less influential in shaping public opinion than appeals to emotion and personal belief. In other words, people use emotions, not facts, to determine truth. Fake news needs these reactions to survive; it circulates mainly on social media, a platform where emotional voices gain popularity (Gillmore, 2017). 
Measures to Check the Spread adopted byDigital platforms

Facebook, in order to show its responsible attitude, started employing "fact checkers" and issued warnings when users would post links to certain stories or websites, as well as outright banning links to some or labelling them "spam" when someone tried to share them. YouTube began demonetizing (removing advertisements from) videos covering certain topics they deemed untrue and fake.

News organizations have responded by setting up fact-checking operations. The Washington Post assigned one of its most senior reporters, Glenn Kessler, to examine and report on statements by politicians that skirt the line between "truthiness," and outright lies. Politi-Fact (www.politifact.com) and Fact Check(www.factcheck.org), do something similar. (Bartlett, 2017)

A recent trend in TV debate is the culture of he said/she said journalism. A politician says something the reporter knows is false, but rather than say so directly the reporter will seek out a spokesman from the opposite side and quote her as saying the politician is lying. The reader is left to figure out the truth.

Even in traditional reporting the problem is that fact checking has become a sort of journalistic ghetto. Reports that correct factual errors don't get anywhere near as much attention as breaking news does. The picture is shady but clear.

\section{Distinguishing Fact from Fiction}

However, there are some key signs to identify if a story is fake. First, fake news articles, however authentic they appear to be on surface, often lack sources. People aren't directly quoted; resource material for statistics may not be provided. Often, legitimate organizations provide links to source information-fake news doesn't. As the stories are all cooked-up.

Another marker is the web address. Some addresses deceptively resemble legitimate news organizations, but have an extra .co after the .com. This can be carefully identified. Also, About Us page on these fake sites do not function, are out of order or non-existent. Another quick option is to re-search any suspicious headlines. If something is true and noteworthy, multiple, respected news organizations will report it in some form or other. Search images, too, as images has a bigger role in deceiving people easily.(Gillmore, 2017)
Critical thinking and intelligent use of technology is the best defense against fake news. The same tools that create fake news can help combat it.

\section{Information literacy}

Information literacy (a phrase that was coined in 1974) describes the meticulous and crafted efforts and attempts of experts to help people think critically about what they read, hear, and share. Explosion of interest in fake news is both a blessing and a curse. The blessing is that the interest in fake news has created a great opportunity for teaching people to become cautiously and consciously more information literate (Barclay, 2018).

Fortunately, the same methods that allow fake news to proliferate provide the tools to fight it. One very simple method is to check whether others are reporting that too-good-to-be-true story. If your source is absolutely the only one with a particular news item, and a search through Google News or a similar source finds no confirmation, it may be that you are being scammed. Of course, everyone likes to be the first to report some hot item to friends, and it's hard to discipline yourself to double-check an item before posting it.

In the end, the best defenses against fake news are critical thinking; taking in news from a variety of sources, including those that don't confirm your own biases; being sceptical about information that sounds too good (or bad) to be true; and other self-defences. To fight fake news by teaching people to be discerning in their news consumption - to tell the difference between news and rumour, news and advertising, news and opinion, bias and fairness.

Similarly, critical thinking is the core function of proper educational system; teaching it in a separate course to fight the scourge of fake news should be superfluous. (Bartlett, 2017)

It will not be an understatement to suggest that social media networks, which currently have an estimated 2.3 billion users worldwide, are facilitating a surge in the dissemination of fake news which have important financial and reputational effects for both conventional and social media companies.

\section{Other Consequences}

A range of investment risks related to fake news; that is, the dissemination of disinformation and hoaxes under the guise of legitimate, factual reporting include regulatory scrutiny, reputational repercussions and genuine financial effects that may hit the bottom line of media 
outlets. As the fake news syndrome continues to develop, there is a growing importance of advanced content governance practices to explore how their media holdings are responding to this syndrome (Vezér, 2017).

\section{Conclusion}

Fake news, lies, rumours, fibs, propaganda-all are synonyms for misinformation. If anything good has come from the recent furore over fake news and its menace, it is that fake news has highlighted the importance of making sure that the information one consumes and, especially, the information one shares is credible.

Perhaps more than at any time in history, people are at least discussing the importance of evaluating information before allowing it to drive their decisions. It is like anti-virus potion which is created automatically. Or in simpler terms, it is like cultivating the habit to consume healthy, hygienic and balanced diet and toning the cognitive immune system.

Information overload makes evaluating information harder than it has ever been in the past. Digital technology makes it easy to distribute fake news to a potentially huge audience at a very low cost. Anyone who uses information faces the lifelong challenge of staying aware of these technologies and learning how to detect and defeat them

Google, Facebook and social media platforms are continuously trying to devise and develop ways to integrate fact checking into their searches and news feeds, but only time will tell whether this will cut down on the spread of falsehoods. User's willingness also plays an important role. Studies have proved that people want to believe in lies because it suits their partisan agenda, ideology, religion, or some other vested interest. People also like and forward fake news when it is interesting or titillating, or when it confirms a core belief or scores points against opponent. (Bartlett, 2017)

Many in the tech community believe it is a problem technology can easily fix. A mixture of efforts are under way to automatically make out fake news stories before they go viral and then either delete them from social media platforms or attach warning statement that the story is unverifiable and possibly fake. Fake News - an unwanted subsystem of digital landscape chokes the very lifeline of communication.

As long as people have a strong incentive to believe a lie, liars will have an equally strong incentive to lie. So fake news will continue to disrupt the media and communication research traffic in the coming years.As poison kills poison, so digital literacy will play a big role in combating the problem of fake news. The chapter on information war will be one defining episode in the history of the future of information age.

\section{References}

\section{Books}

Barclay Donald A, Fake News, Propaganda, and Plain Old Lies: How to Find Trustworthy Information in the Digital Age (Kindle edition) (accessed in Nov, 2018)

Bartlett Bruce, The Truth Matters: A Citizen's Guide to Separating Facts from Lies and Stopping Fake News in Its Tracks Kindle Edition (accessed in Nov, 2018)

Dice Mark, The True Story of Fake News: How Mainstream Media Manipulates Millions, Kindle Edition, (accessed in Nov, 2018)

\section{Articles}

Barthel, M., Mitchell, A. and Holcomb, J. (15.12.2016), "many americans believe fake news is sowing confusion," Pew Research Center, last accessed in Nov, 2018 at: http:/ /www.journalism.org/2016/12/15/ma ny-americans-believe-fake-news-is-sowingconfusion/.

Fisher, M., Woodrow, C. and Hermann, P. (06.12.2016), "Pizzagate: From rumour, to hashtag, to gunfire in D.C.," The Washington Post, last accessed in Nov, 2018 at: https:/ / www.washingtonpost.com/local/piz zagate-from-rumor-to-hashtag-to-gunfire-indc/2016/12/06/4c7def50-bbd4-11e6-94ac3d324840106c_story.html?utm_term $=.97 \mathrm{fca} 97$ 52309 .

Rolling Stone "How a Fake Newsman Accidentally Helped Trump Win the White House" by Erik Hedegaard last accessed in Nov, 2018 at: https:/ / www.rollingstone.com/culture/cult ure-news/how-a-fake-newsman-accidentallyhelped-trump-win-the-white-house-110039/

"Russian propaganda effort helped spread 'fake news' during election, experts say," The Washington Post, last accessed in Nov, 2018 at:

https://www.washingtonpost.com/business /economy/russian-propaganda-efforthelped-spread-fake-news-during-electionexperts-say/2016/11/24/793903b6-8a404ca9-b712-

716af66098fe_story.html?utm_term $=.7 \mathrm{~b} 1723 \mathrm{e}$ 36ef2 
Washington Post "Facebook fake-news writer: 'I think Donald Trump is in the White House because of me" by Caitlin Dewey last accessed in Nov, 2018 at: https://www.washingtonpost.com/news/th e-intersect/wp/2016/11/17/facebook-fakenews-writer-i-think-donald-trump-is-in-thewhite-house-because-ofme/?utm_term $=.42 f 4453 \mathrm{e} 6 \mathrm{be} 8$

Washington Post "Russian propaganda effort helped spread 'fake news' during election, experts say" by Craig Timberg (November 24th 2016), last accessed in Nov, 2018 at: https://www.washingtonpost.com/business /economy/russian-propaganda-efforthelped-spread-fake-news-during-electionexperts-say/2016/11/24/793903b6-8a404ca9-b712-

716af66098fe_story.html?utm_term $=. b 72 \mathrm{~d} 237$ 15044

\section{Websites}

http:/ / www.astridonline.it/static/upload/hubb/hubbards_www.forbes_10_01_17.pdf (accessed in Nov, 2018)

http://www.journalism.org/2017/09/07/newsuse-across-social-media-platforms-2017/ (accessed in Nov, 2018) https://www.researchgate.net/publication/3172 89773_Fake_news_social_media_and_the_val ue_of_credible_content (accessed in Nov, 2018)

https://www.researchgate.net/publication/3233 83944_The_fake_news_game_actively_inocul ating_against_the_risk_of_misinformation (accessed in Nov, 2018)

https://www.researchgate.net/publication/3172 89773_Fake_news_social_ media_and_the_value_of_credible_content (accessed in Nov, 2018)

CNN "Facebook censorship under the microscope" by Sarah Ashley O'Brien (February 4th 2016)https://money.cnn.com/2016/02/04/te chnology/online-censorship-facebooktwitter/index.html (accessed in Nov, 2018)

http://teachmag.com/archives/9860 Fake News: Distinguishing Fact from Fiction, by Meagan Gillmore (accessed in Nov, 2018)

https://www.researchgate.net/publication/3172 89773_Fake_news_social_media_and_the_val ue_of_credible_content (accessed in Nov, 2018) 